\title{
Effectiveness of Social Media in Learning Anatomy among Students Studying in First-Year M.B.B.S., - A Prospective Study
}

\author{
Dr. Deepa Bently $\mathbf{J}^{1}$, Dr. Rieyaz H. A ${ }^{2 *}$, Dr. Denesh Kumar V ${ }^{3}$
}

${ }^{1}$ Professor \& Head of Anatomy, GMC \& ESICH, Coimbatore, Tamilnadu, India

${ }^{2}$ Assistant Professor of Anatomy, Coimbatore Medical College, 1 A, SF No 498, Avinashi Rd, Civil Aerodrome Post, Peelamedu, Coimbatore, Tamil Nadu 641018, India

${ }^{3}$ Assistant Professor of Statistics, Manonmanian Sundaranar University, Abishekapatti, Tirunelveli, Tamil Nadu, 627012, India

*Corresponding author: Dr. Rieyaz H. A

\section{Abstract}

Background: In the current era of globalization and modernization teaching - learning methods employed in medical education needs revamping to keep pace with the changing trends in teacher-student interactions and teaching-learning methods. Social media as an educational tool seems to be a promising adjunct to impart medical knowledge to the millennial minds. So, the current study was done with students studying anatomy in first year M.B.B.S $2017-2018$ batch at GMC \&ESICH, CBE to evaluate the usefulness of social media as an educational tool in learning anatomy. Aims \& Objectives: To assess the impact and usefulness of social media in learning anatomy among students studying in first year M.B.B.S 2017 - 2018 batch at GMC \&ESICH, CBE for a period of one year. Material and Methods: A questionnaire was prepared containing 9 questions pertaining to the usefulness of social media as a tool in the learning anatomy after getting ethical clearance. The same was given to 100 students studying in the first-year MBBS and their responses were collected and evaluated statically. Results: Out of 100 questionnaires distributed, all were completed, collected and evaluated (response rate: 100\%). Of 100 students, $86 \%$ students felt that using social media helped them to understand the subject better, $81 \%$ students felt that social media tools they used made their learning experience enjoyable and subjects interesting, $67 \%$ students felt that they were motivated to learn more through social media and that they could inculcate the habit of learning through social media with ease, $52 \%$ of students answered positively for usefulness for all topics, $44 \%$ of students answered excellent as their overall rating, $41 \%$ of students felt that using social media tools was more time consuming, 38\% of students felt that it was useful for preparing and facing their various theory and practical examinations, $16 \%$ of students reported using social media regularly for their study of anatomy. Conclusion: Social media seems to be a promising tool in medical education in the light of changing trends of education. Judicial use of the same may facilitate better learning, understanding, and application of acquired knowledge.

Keywords: Subject, Students, Social media, Learning, Medical Education.

Copyright @ 2019: This is an open-access article distributed under the terms of the Creative Commons Attribution license which permits unrestricted use, distribution, and reproduction in any medium for non-commercial use (NonCommercial, or CC-BY-NC) provided the original author and source are credited.

\section{INTRODUCTION}

The millennial generation is unique not only in their way in which they learn but also in the learning environment conducive to their learning is unique. Having been exposed to multimedia at an early age, the age-old conventional teaching-learning methods may not appeal to their minds.

Hence it may be necessary for teachers at large, including medical teachers to include not only various multimedia platforms in classroom learning but also judiciously employ various social media platforms to achieve quality education instead of resorting to ageold methods.
Medical education is tedious and timeconsuming. The stipulated time allocated for studying each subject is hardly sufficient to master it. A student of medicine has to do hard work outside the classroom to reinforce and remember the topics covered in the classrooms to gain wholesome knowledge which is necessary for application on patients throughout their career. Conventionally medical students study outside the classrooms using textbooks and various reference books. The current generation seems to get more knowledge from non-textbook sources including the internet and social media. Most of our students use various social media platforms for socializing and 
perusing their other extra-curricular activities on a daily or more frequent basis.

Gaining knowledge in medical subjects from such platforms to improvise their knowledge in the topics taught in classrooms seems to be more enjoyable and convenient for them.

\section{MATERIALS AND METHODS}

In the undergraduate medical curriculum Anatomy is considered as the basic and first subject to be taught and learned in their medical school. The majority of students find it difficult to study this subject through the age-old teaching-learning methods used like didactic lectures and dissection. To make the subject more interesting, to gain a better understanding and 3D orientation students have started using social media. In this present study, a questionnaire was prepared containing 9 questions pertaining to the usefulness of social media as a tool in the learning Anatomy and was given to 100 students studying in the first year M.B.B.S 2017 - 2018 batch (39 male and 61 female) studying in GMC \& ESICH, CBE.

The purpose of the study was intimated to the students and informed consent was obtained from all after getting clearance from the ethical committee. The students were in the age group 18-22 years; all were using android mobile and social media. There were no Students with non-android mobile phones or not using social media platforms. The parameters tested were usefulness for all topics, understanding of the subject, helpfulness for the exam, time consumption compared to other modes of learning and making subjects interesting, motivation to learn, rating its usefulness, how often social media is being used to study anatomy. The feedback forms were collected back and the data were electronically interpreted, recorded and their response to various parameters was analysed statistically.

\section{RESULTS}

A wide majority of students $(86 \%)$ felt that social media helped them to understand the subject better. Most of them $(81 \%)$ felt that social media made the learning experience interesting and motivated to learn better $(67 \%) .52 \%$ of students responded that it was useful for studying all topics and (54\%) found it of good help to face the various theory and practical examinations. However, only (14\%) reported to the regular users of social media and $50 \%$ found it was to be more time consuming than textbook learning. The observations were noted and tabulated in table 1 and Figure-1.

Table-1: Shows the Response to different questions as tabulated

\begin{tabular}{|l|l|l|l|}
\hline Parameter assessed & Number of responders (percentage) \\
\hline Question & Yes or more & Little & No \\
\hline Usefulness for all topics & $52 \%$ & $42 \%$ & $6 \%$ \\
\hline Understanding of the subject & $86 \%$ & $13 \%$ & $1 \%$ \\
\hline Helpfulness for exam & $38 \%$ & $54 \%$ & $8 \%$ \\
\hline Time consumption compared & $41 \%$ & $50 \%$ & $9 \%$ \\
\hline Makes subjects interesting & $81 \%$ & $18 \%$ & $1 \%$ \\
\hline Motivates your learning & $67 \%$ & $29 \%$ & $4 \%$ \\
\hline Question & Excellent & Moderate & Not useful \\
\hline How will you rate its usefulness & $44 \%$ & $55 \%$ & $1 \%$ \\
\hline Question & Regularly & Discontinuously & Not be using \\
\hline How often will be using it & $16 \%$ & $82 \%$ & $2 \%$ \\
\hline Question & Always & Rarely & Not using \\
\hline Do you use social media & $22 \%$ & $73 \%$ & $5 \%$ \\
\hline
\end{tabular}

Fig-1: Shows the Response to different questions as depicted as a bar diagram

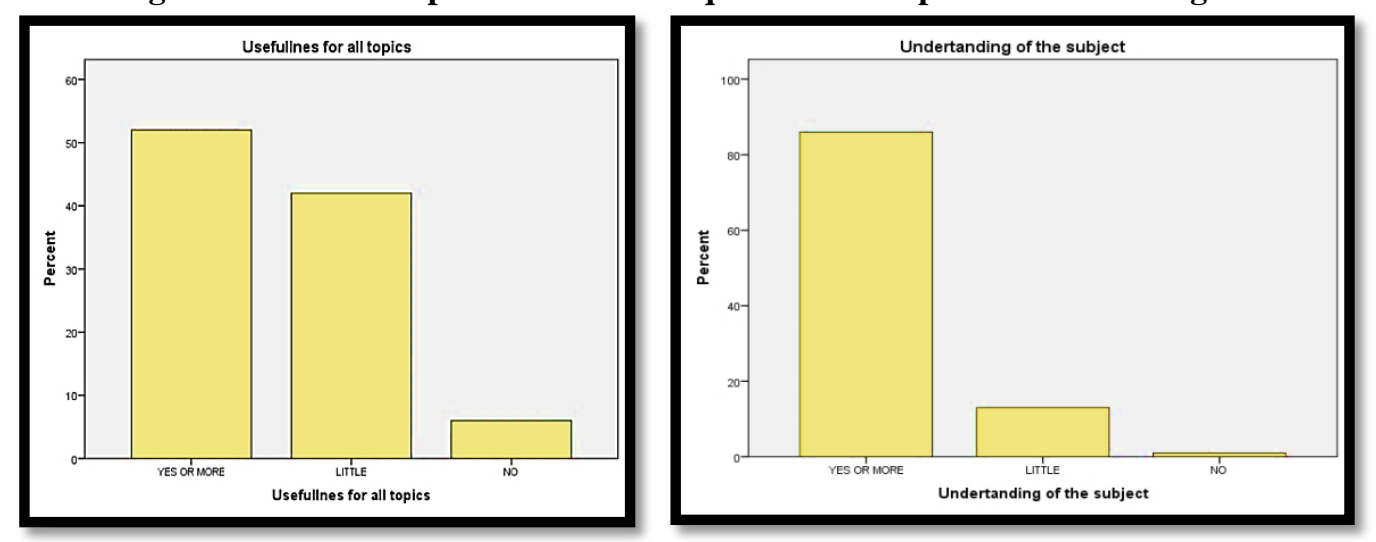



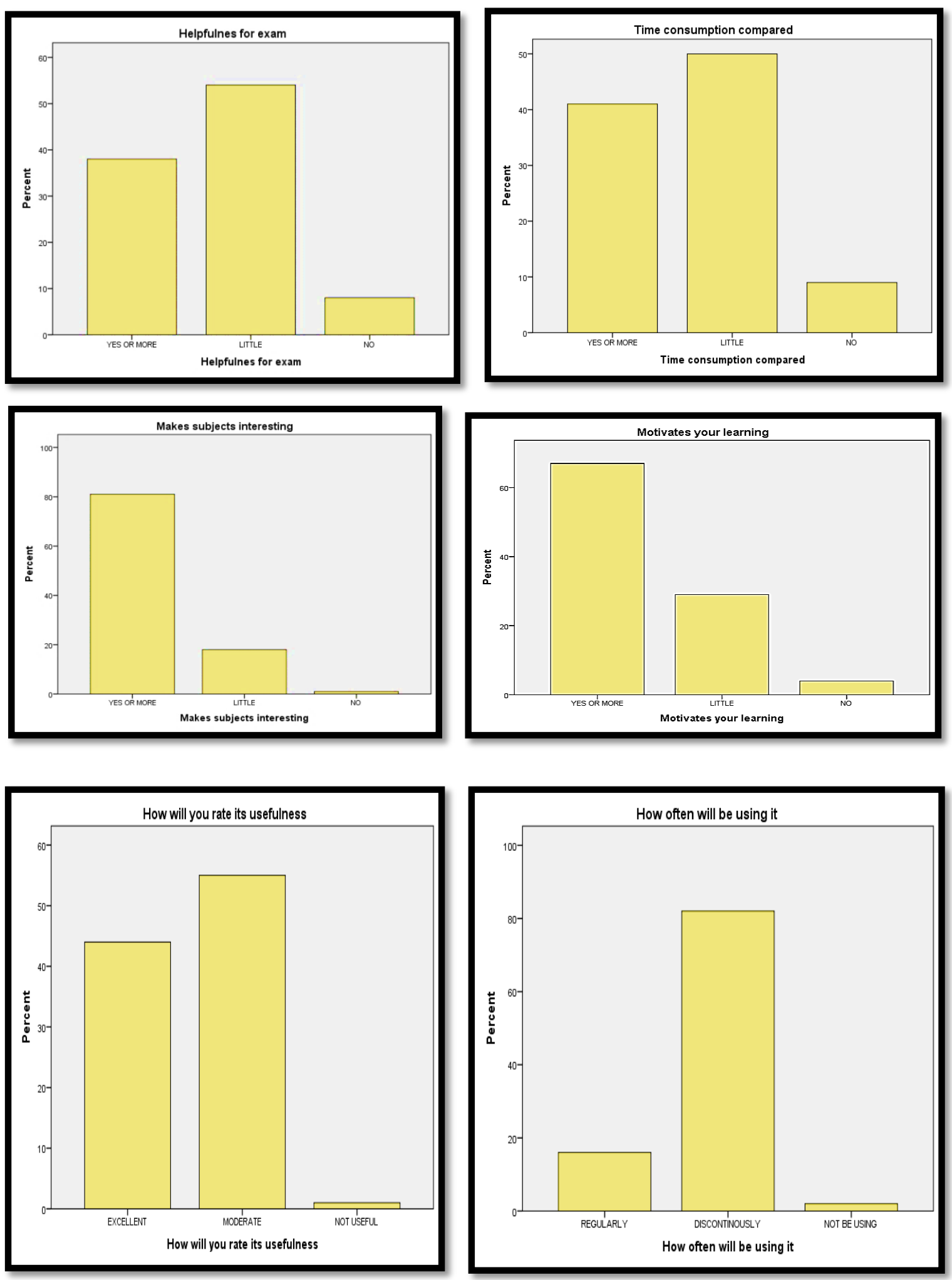


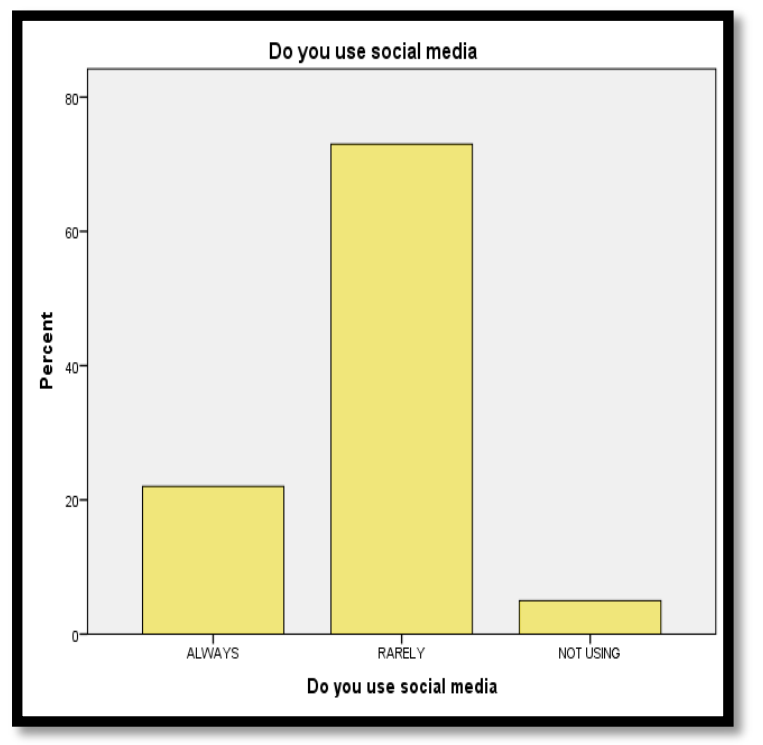

\section{DISCUSSION}

The term "Social Network was coined by Barnes in 1954 explaining that it is a social relationship among the groups, individual and social structure. This kind of relationship is either intimate or just simple encounters [1].

According to the Waite. $\mathrm{M}$ and Dictionaries $\mathrm{O}$ social media is defined as applications and websites which are used to create and share content, help in interaction with other users or to find people with similar interests to one's own. Multiple platforms are ranging from blogs/micro blogs (Twitter) through to wikis, YouTube and social network sites such as Facebook which are useful in learning Anatomy [2].

Recent developments in information technology, when used in medical education help in bridging the gap, enlightens the knowledge, and give better orientation, understanding. Because of increased numbers of followers using social networking browsers not only for entertainment purposes and also for learning purposes wherever they want according to their feasibility. A Few examples are Facebook, Twitter, Skype, YouTube, Google+, Instagram, Research Gate, etc. [3].

In 2013 Cheston et al, stated that, Wikipedia plays an important role as a fast searching engine and analysing the topics in primary level for the browsers, also Wikipedia with over 5.3 million published articles in medicine and averaging 800 new articles a day, so this will be most widely used form of social media [4].

According to Kennedy et al., In 2008, current generation people are net generation because of increased usage of social media in medical schools and that usage of applicants is also increased [5].
Bennett et al., In 2008 and Pander et al., in 2014 stated that in the current generation individuals are exposed to digital technology from their young age and use it for their learning and entertainment purposes on a day- to-day basis and their learning is kindled through social media. [6]. The same was reflected in our study in which students felt that social media had a positive influence on their learning of anatomy [7].

In the year 2011, Hew et al., conducted a study among learners and teachers regarding the use of Facebook. The reviews reported in the study were that Facebook has its limitations similar to the didactic method. In our study though we did not ascertain the relative usefulness of the different social media platforms, we have received a positive response that learning through social media is useful [8].

In the year 2014, Jaffar's et al., observered that usage of social media among students was gradually increasing over the years, in 2012, $86 \%$ of students used social media. In 2013 it was increased to $92 \%$. In our study, $100 \%$ of students have used social media for studying anatomy and the majority of $86 \%$ responded that it helped them to study better [9].

In 2014, Usher et al., stated that among medical students $93 \%$ used social media platforms like Facebook. Amongst older students of usage of social media is less when compared to younger students due to potential lack of familiarity. Our study was conducted among first- year medical students only. Among them, $86 \%$ were finding it useful and $16 \%$ were regular users [10].

People of Today's generation prefer the virtual world for their learning as well as entertainment purposes. Most of them possess multiple social media accounts. This is a great benchmark in the history of information technology. Social media offers a platform 
for healthy discussion among learners it also facilitates field. This helps everyone involved to gain wholesome knowledge and easy elimination of doubts [11].

Current generation learners prefer the connectivist method of learning [12] i.e. expecting better bondage with the teachers in the form of communication, without any restriction for contacting them for learning. Social media learning provides the same promoting healthy teacher-student relationship. The study was conducted at the Afyon Kocatepe University by Avci K et al., in 2016, stated that one of the social media platforms i.e. twitter was their teaching tool, they found that students were efficient and effective to their learning, it shows strengthened student-teacher relationship [13].

This methodology of learning not only shows greater autonomy for learners and also a changing role for the teachers, rather than collapsed distinct between teachers and students. In our study, we achieved connectivist learning through social media [14].

In the medical University of Ottawa, the study conducted by El Bialy et al stated that the majority of educators not using social media for learning purposes. The reason behind this was privacy issues, timewasting, distraction, because of this kind of mode of learning might not be suitable for education. In routine academic work, some educators don't use social media due to a lack of awareness. Some educators used social media routinely in the form of post their articles, comments, video clippings, post-lecture comments, recommended books, revision files, quizzes, and study-related humor. Again in El Bialy et al., studied in another group of students who use social media regularly for their learning, they stated that it was time-effective, inviting to create interest for learning, improvement in their academic performance shows similar to our study. While in the current study students felt that using social media was more time consuming [15].

The study was conducted among medical universities in Saudi Arabia by Alsuraihi AK et al., in 2016, stated that $95.8 \%$ of the students felt that social media learning was beneficial, $40 \%$ of the students thought using social media might be distracting during the period of learning. While in the current study $86 \%$ found it beneficial [16].

In the Penn state college of medicine, a pilot study was conducted by George et al., evaluating the integration of Skype, Blogging, Flicker, YouTube, and Twitter among final year medical students in two different elective courses. This study result shows a positive response among students enrolled in the new integration teaching methodology. Because of this, their medical education unit strongly recommended the integration of social media in the routine academic curriculum will enhance their learning as well as in their performance in examinations. In the current study, the majority of students were satisfied and happy with the use of social media [17].

In the western world, several medical schools have been recommended learning through social media and it shows the gross difference in the learning habits and academic performance [18]. So it was incorporated as a part of their medical educational curriculum [19].

In the United States of America, almost 132 medical schools have a website and the majority around $95 \%$ of students are actively participating in Facebook. Among these schools, $26 \%$ have official medical school SM pages and $71 \%$ have student groups [20].

In the year 2008, association for the advancement of computing in education (AACE) conducted international conference in Las Vegas, Nevada, USA, in that Ozkan and McKenzie presented their paper, mentioned as Social Networking Tools for Teacher Education, in Proceedings of Society for Information Technology \& Teacher Education contend that educators need to engage students with a more $21 \mathrm{st}$ century approach to teaching and social networking technologies can provide such a venue [21].

In the current study showed similar reflections from the students that social media was effective in their academics by creating more enthusiasm in reading, kindling their clinical skills and learning, also make their learning atmosphere fun and lively without distracting the learners. In spite of all comments, learning through social media makes learners more active participation, building their interactive learning skills, engaging in more creative works and finally collaborating with their ideas and skills to their learning. Finally is the responsibility of the educators to guide the students and judicially use the various social media platforms and integrate them [22].

\section{CONCLUSION}

The usage of social media is emerging as an effective tool in medical education. When it is integrated with the new competency-based medical education (CBME) promulgated by the medical council of India, it will facilitate the proposed learner-centric method of delivering medical education.

\section{Funding: Nil \\ Conflict of interest: None}

\section{REFERENCES}

1. Barnes, J. A. (1954). Class and committees in a Norwegian island parish. Human relations, 7(1), 39-58.

2. Waite, M. (Ed.). (2012). Paperback Oxford English dictionary. Oxford University Press.

3. Jong, B. S., Lai, C. H., Hsia, Y. T., Lin, T. W., \& Liao, Y. S. (2014). An exploration of the potential 
educational value of Facebook. Computers in Human Behavior, 32, 201-211.

4. Cheston, C. C., Flickinger, T. E., \& Chisolm, M. S. (2013). Social media use in medical education: a systematic review. Academic Medicine, 88(6), 893-901.

5. Bennett, S., Maton, K., \& Kervin, L. (2008). The 'digital natives' debate: A critical review of the evidence. British journal of educational technology, 39(5), 775-786.

6. Kennedy, G., Gray, K., \& Tse, J. (2008). 'Net Generation'medical students: technological experiences of pre-clinical and clinical students. Medical teacher, 30(1), 10-16.

7. Pander, T., Pinilla, S., Dimitriadis, K., \& Fischer, M. R. (2014). The use of Facebook in medical education-A literature review. GMS Zeitschrift für Medizinische Ausbildung, 31(3).

8. Hew, K. F. (2011). Students' and teachers' use of Facebook. Computers in human behavior, 27(2), 662-676.

9. Jaffar, A. A. (2014). Exploring the use of a Facebook page in anatomy education. Anatomical sciences education, 7(3), 199-208.

10. Usher, K., Woods, C., Casella, E., Glass, N., Wilson, R., Mayner, L., ... \& Cummings, E. (2014). Australian health professions student use of social media. Collegian, 21(2), 95-101.

11. Kalia, G. (2013). A research paper on social media: An innovative educational tool. Issues and Ideas in education, 1(1), 43-50.

12. Couros, A. (2009). Open, connected, socialimplications for educational design. Campus-wide information systems, 26(3), 232-239.

13. Avcı, K., Çelikden, S. G., Eren, S., \& Aydenizöz, D. (2015). Assessment of medical students' attitudes on social media use in medicine: a cross- sectional study. BMC medical education, 15(1), 18.

14. Paul, S., Pusic, M., \& Gillespie, C. (2015). Medical student lecture attendance versus iT unes U. Medical education, 49(5), 530-531.

15. El Bialy, S., \& Jalali, A. (2015). Go where the students are: a comparison of the use of social networking sites between medical students and medical educators. JMIR medical education, 1(2), e7.

16. Alsuraihi, A. K., Almaqati, A. S., Abughanim, S. A., \& Jastaniah, N. A. (2016). Use of social media in education among medical students in Saudi Arabia. Korean journal of medical education, 28(4), 343.

17. George, D. R., \& Dellasega, C. (2011). Social media in medical education: two innovative pilot studies. Medical education, 45(11), 1158-1159.

18. Davis, W. M., Ho, K., \& Last, J. (2015). Advancing social media in medical education. CMAJ, 187(8), 549-550.

19. Jalali, A., \& Wood, T. J. (2014). Teaching medical students social media: must or bust. Medical education, 48(11), 1128-1129.

20. Kind, T., Genrich, G., Sodhi, A., \& Chretien, K. C. (2010). Social media policies at US medical schools. Medical education online, 15(1), 5324.

21. Ozkan, B., \& McKenzie, B. (2008). Social networking tools for teacher education. In Society for Information Technology \& Teacher Education International Conference (2772-2776). Association for the Advancement of Computing in Education (AACE).

22. Rajendran, R., \& Joena, V. (2017). Effectiveness of social media as a medical teaching tool. International Journal of Medical Research and Review, 5(4), 381-385. 